\title{
EXPERIMENTAL INVESTIGATION OF DAMAGE EVOLUTION IN CONCRETE UNDER HIGH-CYCLE FATIGUE
}

\author{
MARC THIELE ${ }^{*}$, YURI PETRYNA $^{\dagger}$ AND ANDREAS ROGGE ${ }^{\dagger \dagger}$ \\ BAM Federal Institute for Materials Research and Testing \\ Unter den Eichen 87, 12205 Berlin, Germany \\ e-mail: marc.thiele@bam.de \\ ${ }^{\dagger}$ Technische Universität Berlin \\ Gustav-Meyer-Allee 25, 13355 Berlin, Germany \\ e-mail: yuriy.petryna@tu-berlin.de \\ BAM Federal Institute for Materials Research and Testing \\ Unter den Eichen 87, 12205 Berlin, Germany \\ e-mail: andreas.rogge@bam.de
}

Key words: Fatigue, Concrete, High-Cycle, Damage Evolution

\begin{abstract}
The current knowledge about fatigue behavior of concrete is still incomplete. This concerns especially the progress of fatigue which precedes the fatigue failure. Therefore, the process of fatigue itself under cyclic compressive loading was investigated in a systematic and comprehensive way. The aim of this investigation was to obtain a deeper insight and to provide a better understanding of the damage process occurring within the material during fatigue loading. Concrete cylinders were tested with a number of cycles to failure between $10^{6}$ and $10^{7}$. To investigate macroscopic and microscopic changes in the material, various methods of nondestructive and destructive testing were used. One main result was, in contrast to other authors, that the investigated changes in macroscopic material behavior could not be explained only by a development of micro-cracks. The results indicated rather, that the related changes in the fatigue behavior are mainly a result of viscous processes in the hardened cement paste, similar to the processes of creep. Based on the experimental results a description of the possible processes was derived which take place in the material structure during fatigue loading and also leads to the observed macroscopic changes in the material behavior. In this context, the results have shown that in case of isotropic material behavior a stiffness reduction related to a scalar value could not capture the damage effect on the stress-strain-relationship caused by fatigue.
\end{abstract}

\section{INTRODUCTION}

Fatigue behavior of concrete has been a part of research on concrete since over 100 years [20]. In spite of this long history of research and numerous scientific works today, there are still many gaps of knowledge in regard to fatigue of concrete. Reasons for this fact can be found in the complex material behavior of the heterogeneous concrete as well as in the expensive experiments that are necessary. In contrast to this situation the subject of concrete fatigue becomes more and more relevant. The part of cyclic loads in structures is still growing as a result of the trend to filigree structures, an increasing traffic as well as new fields of application, e.g. offshore wind 
energy.

Most of the previous investigations were focused on the fatigue strength and associated influence factors. Meaning that the numbers of cycles until fatigue failure were typically count for derivation of S-N-curves for different types of concrete as well as for different load levels. Examples are the works of $[4,5,9,10,12,13$, 17, 21]. The process of fatigue itself, which takes place in the material through the complete cyclic loading and finally leads to the fatigue failure, is still less investigated. That applies especially for high-cyclic loading. Thereby changes in the material structure and the material behavior taking place through the whole fatigue process.

Some previous works considered particularly low-cycle behavior at which tension and compression loading has to be differentiated. Thereby also the fatigue process was partially considered with the help of nondestructive and destructive testing methods. E.g. $[1,14,15]$ have studied the process of compressive cyclic loadings. The fatigue process under tension or bending cyclic loading was analyzed by e.g. [2, 19]. The knowledge about concretely crack development is very rarely available. This was predominantly investigated for the field of low-cycle tension loadings, e.g. [16, 19]. And only a few results exist for the range of cyclic compressive loadings.

Results for relevant high-cycle compressive loadings are also rarely available. Only a few authors have partly done some investigation in relation to fatigue process within the investigations of fatigue strength. However, this is all very fragmentary. In this context for example the works of $[3,6,7,8,11]$ can be referred. Systematic investigations of the fatigue process under high-cycle compressive loading together with various non-destructive and destructive testing methods are currently not available as far as the author knows.

Therefore the goal of the presented work was to investigate the fatigue process of concrete under high-cycle compressive loading at the macro- as well as at the micro-level. Based on the relevant knowledge of the existing research, systematic experimental investigation of the fatigue process was done. For that various methods of non-destructive and destructive testing were used to get a better understanding of the processes in the material structure. This paper is presenting a part of the performed experiments and the obtained results, which can be found in detail in [18].

\section{MATERIAL AND EXPERIMENTAL SETUP}

Within this experimental investigation only one concrete mixture was used. This is a result of the intention of this project to be focused on the principal damage process which occurs during cyclic loading of concrete. Therefore a simple normal strength concrete of grade C40/50 was used. Table 1 shows the composition of the concrete mixture.

Table 1: Composition of the used normal strength concrete

\begin{tabular}{ccccc}
\hline $\begin{array}{c}\text { w/c } \\
\text { ratio } \\
{[-]}\end{array}$ & water & cement & $\begin{array}{c}\text { super } \\
\text { plast. } \\
{\left[\mathrm{kg} / \mathrm{m}^{3}\right]}\end{array}$ & $\begin{array}{c}\text { aggreg } \\
\text { ates } \\
{\left[\mathrm{kg} / \mathrm{m}^{3}\right]}\end{array}$ \\
\hline 0.461 & 169 & 375 & 5.25 & 1,815 \\
\hline
\end{tabular}

For the fatigue test cylindrical specimens with $d / h=1 / 3$ were chosen (see Figure 1 ). The ratio of $\mathrm{d} / \mathrm{h}=1 / 3$ is needed to get an undisturbed loading area in the middle part of the specimen for the experiments.

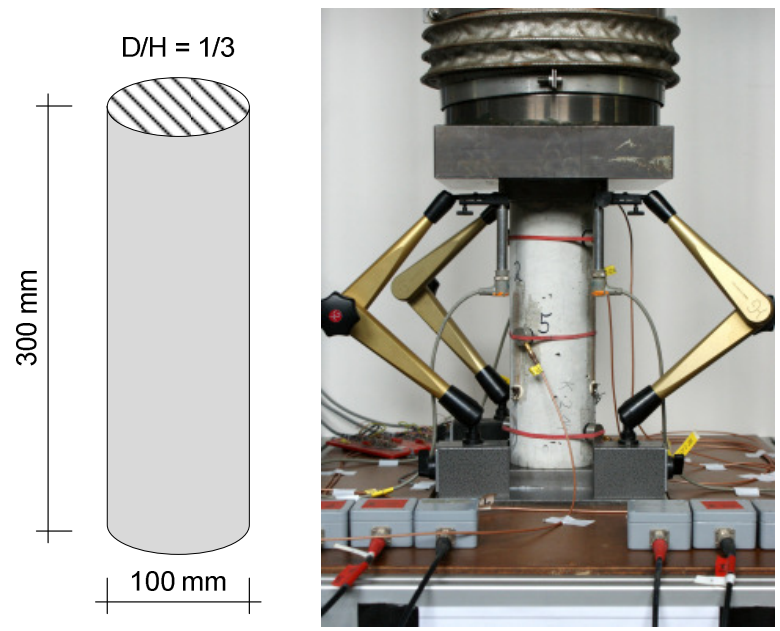

Figure 1: Dimensions of specimens (left) and specimen in test configuration (right). 
The boundary area of the specimen is strongly influenced because of the much lower transverse strain of the steel loading plates from the testing rig. A sketch of the specimen shape and a picture of a specimen in testing configuration are shown in Figure 1.

The average 28-day compressive strength of cubes with $150 \times 150 \mathrm{~mm}$ was $64 \mathrm{~N} / \mathrm{mm}^{2}$ and for the cylinders $55 \mathrm{~N} / \mathrm{mm}^{2}$. A constantamplitude cyclic compressive load was applied to the specimens. The used loading program is schematically shown in Figure 2 and consists of sine waves which are interrupted in regular intervals for purpose of measuring. At this section different kinds of loading ramps were performed including a complete loading and unloading as a hysteresis.

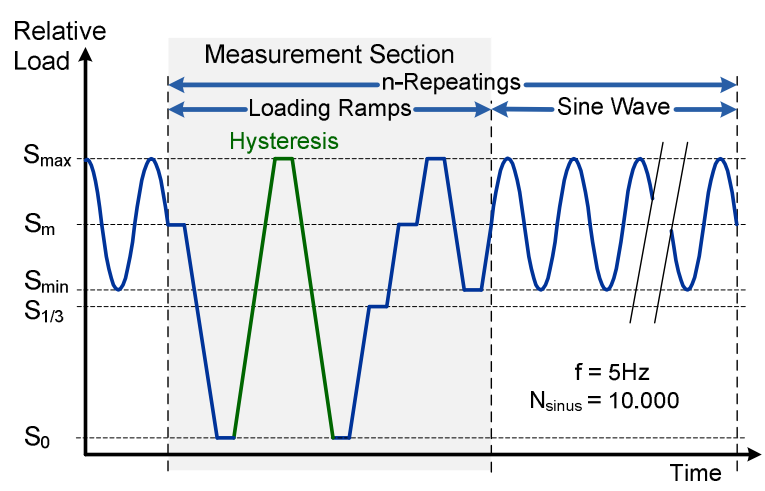

Figure 2: Loading scheme for fatigue tests.

The different load levels were chosen in such way that fatigue failure occurs after approximately $10^{6}$ load cycles. The load values are given in Table 2.

Table 2: Load values for high-cyclic loading

\begin{tabular}{ccccc}
\hline Load & $\mathrm{S}_{0}$ & $\mathrm{~S}_{\min }$ & $\mathrm{S}_{\mathrm{m}}$ & $\mathrm{S}_{\max }$ \\
\hline $\mathrm{S}[-]$ & 0.01 & 0.35 & 0.55 & 0.75 \\
$\mathrm{~F}[\mathrm{kN}]$ & 5 & 152 & 239 & 326 \\
$\sigma\left[\mathrm{N} / \mathrm{mm}^{2}\right]$ & 0.66 & 19.9 & 31.1 & 42.7 \\
\hline
\end{tabular}

They are determined as relative load values normalized by the static compressive strength.

$$
S_{\max }=\sigma_{\max } / f_{c}
$$

In principle a 3-phased process of evolution occurs during the fatigue process in the concrete which is schematically illustrated in
Figure 3. Phase I reaches up to $10-20 \%$ of fatigue life. Strong changes take place in this phase which decay to the end of phase I. Phase II is running up to $80-90 \%$ of fatigue life and shows a stabilized evolution of changing. In phase III the changes are strongly increasing and the behavior becomes instable until the failure occurs.

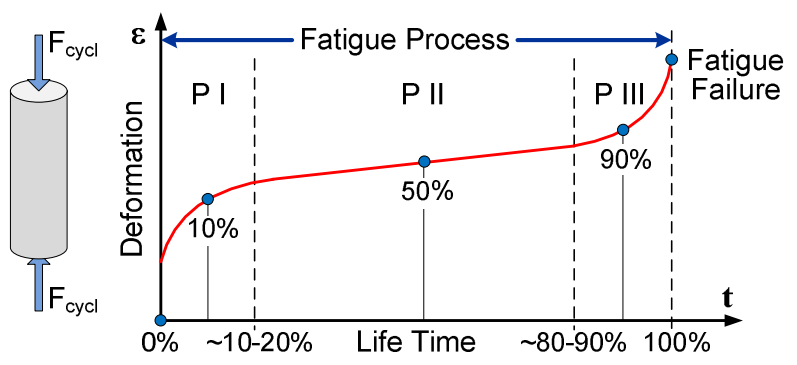

Figure 3: General typical development of fatigue process in concrete with 3 phases.

All fatigue experiments were monitored with manifold kinds of measuring methods. Applied non-destructive methods were measuring the stains with strain gauges, surface deformations with the system ARAMIS from GOM Company, acoustic emissions, ultrasonic signals, E-moduli as well as stress-strain-relationship out of hysteric load loops. Residual static strength tests, optical microscopy as well as electron scattering microscopy were used during destructive investigations.

The non-destructive methods were applied in a series of tests which were performed up to fatigue failure. To carry out the destructive methods specimens were loaded to different certain points of fatigue life. This was only possible by a new developed method which estimates the current status of fatigue life during the fatigue tests based on the findings of the $100 \%$ fatigue tests. Using this method, specimens reaching $90 \%, 50 \%$ and $10 \%$ of fatigue life were generated. Additionally, some new and totally unloaded specimens were also investigated.

\section{EXPERIMENTAL RESULTS}

Within the framework of this investigation 34 specimens were tested and investigated 
under high-cycle loading. Table 3 shows the loading cycles reached and also the duration of the tests.

Table 3: Load cycles and duration for highcycle fatigue tests

\begin{tabular}{cccc}
\hline $\begin{array}{c}\text { Number of } \\
\text { Specimens }\end{array}$ & $\begin{array}{c}\text { Load } \\
\text { Cycles }\end{array}$ & Average & Duration \\
\hline 34 & $210,000-$ & 4.0 Mio & $\begin{array}{c}22 \mathrm{~h}-36 \\
\text { days } \\
14.6 \mathrm{Mio}\end{array}$ \\
\hline
\end{tabular}

The received results can be differentiated in macroscopic and microscopic observations. Therefore, they are presented separately in the following.

\subsection{Macroscopic observations}

General knowledge about macroscopic fatigue behavior, like strain development or fatigue load cycles, can be found in several publications, e.g. $[7,8,10,13,21]$. In contrast the present results are focused on substantial changes in relation to fatigue process in the material.

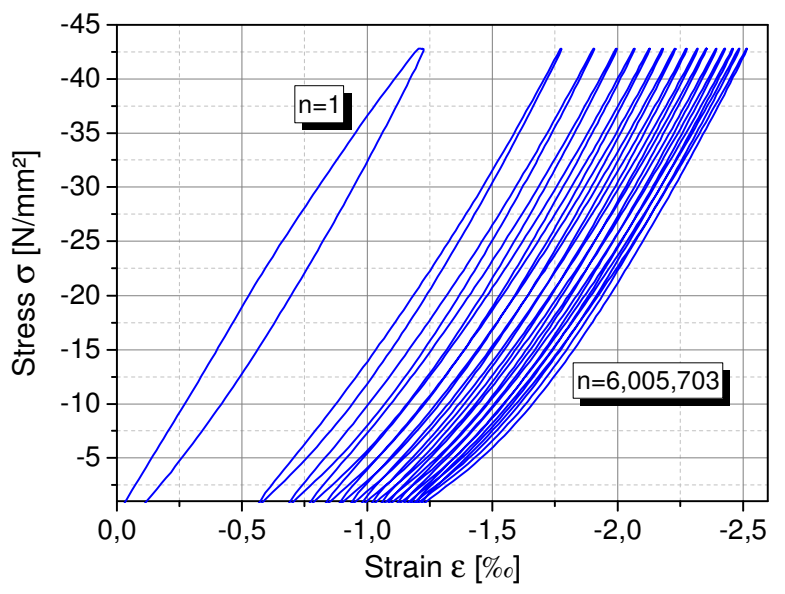

Figure 4: Stress-strain-relationship determined at hysteric loops every 400,000 load cycles.

The main effect on the material behavior exhibits in the change of the stress-strainrelationship. The cyclic loading leads to a changing process from the beginning where the stress-strain-relationship is continuously modified. This process has a 3-phased evolution like the illustrated curve in Figure 3. In regular intervals the stress-strain- relationship was determined between the load levels $S_{0}$ and $S_{\max }$. Such a recorded evolution of the stress-strain-relationship is illustrated in Figure 4. In this diagram 400,000 load cycles are between each hysteric loop. The last hysteresis was measured shortly before fatigue failure.

It can be seen that the loading curve becomes a curvature reversal in phase I. The relation between stress and strain becomes more and more nonlinear. So, the material behavior changes partly significantly.

An indication of the processes in the material is given by the measured acoustic emissions. They are generated in the specimens by crack initiation, crack growth and friction of crack surfaces. With piezoelectric sensors which are mounted on the specimen surfaces these acoustic emissions were directly detected during the tests. A typical development of the acoustic emission hit rate during the fatigue life is illustrated in Figure 5.

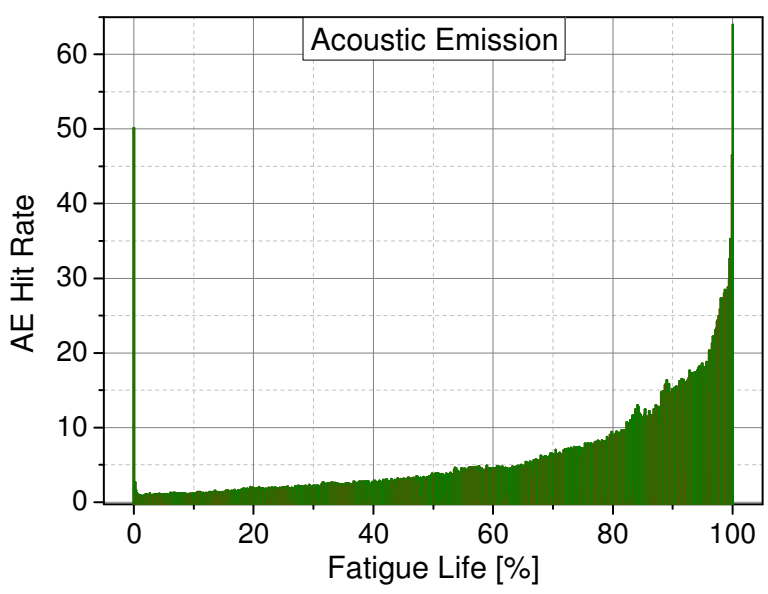

Figure 5: Typical development of acoustic emission hit rate over fatigue life.

Here a 3-phased evolution can be again determined. During the first loadings a very high acoustic activity is measured. However, after that the hit rate reaches rapidly a minimum and increases slowly during phase II. Only at the end of fatigue life in phase III the hit rate shows an exponential increase which indicates a high micro-crack generation. 


\subsection{Microscopic observations}

The states and changes in the material structure were investigated by non-destructive as well as destructive methods.

Initial state: Concrete is characterized through his strongly heterogeneous structure which basically consists of aggregates, hardened cement paste, interfacial transition zones and voids. Because all of them have very different material properties complex interactions take place.

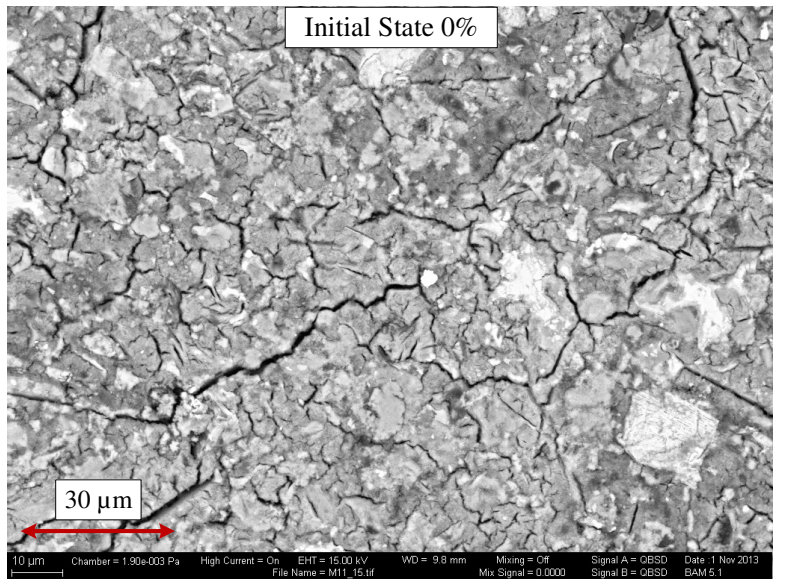

Figure 6: Typical micro-crack structure within hardened cement paste taken by SEM.

The pictures from totally new and unloaded concrete taken by SEM show a fine and distinct structure of micro-cracks at the hardened cement paste. Figure 6 shows exemplary such a structure of micro-cracks in hardened cement paste.

It is assumed that distinct internal stresses are generated in the material structure based on the different material properties of the components especially during the process of hydration. This leads finally to tension stresses in the hardened cement paste and thereby to a distinct and arbitrary oriented structure of micro-cracks.

Load distribution under cyclic loadings: Under exterior loading respectively during cyclic loading of concrete a very inhomogeneous stress and strain distribution appears in the material structure based on the high heterogeneity of concrete. The aggregates act stiffer and more elastic while the hardened cement paste acts weaker and visco-plastic. Thereby complex multi axial stress states arise in the concrete in spite of uniaxial exterior loading. With the measuring system ARAMIS it was possible to determine strain distribution based on digital image correlation at the surface of the specimen. In Figure 7 the measurement at a point of $50 \%$ fatigue life is illustrated exemplary.
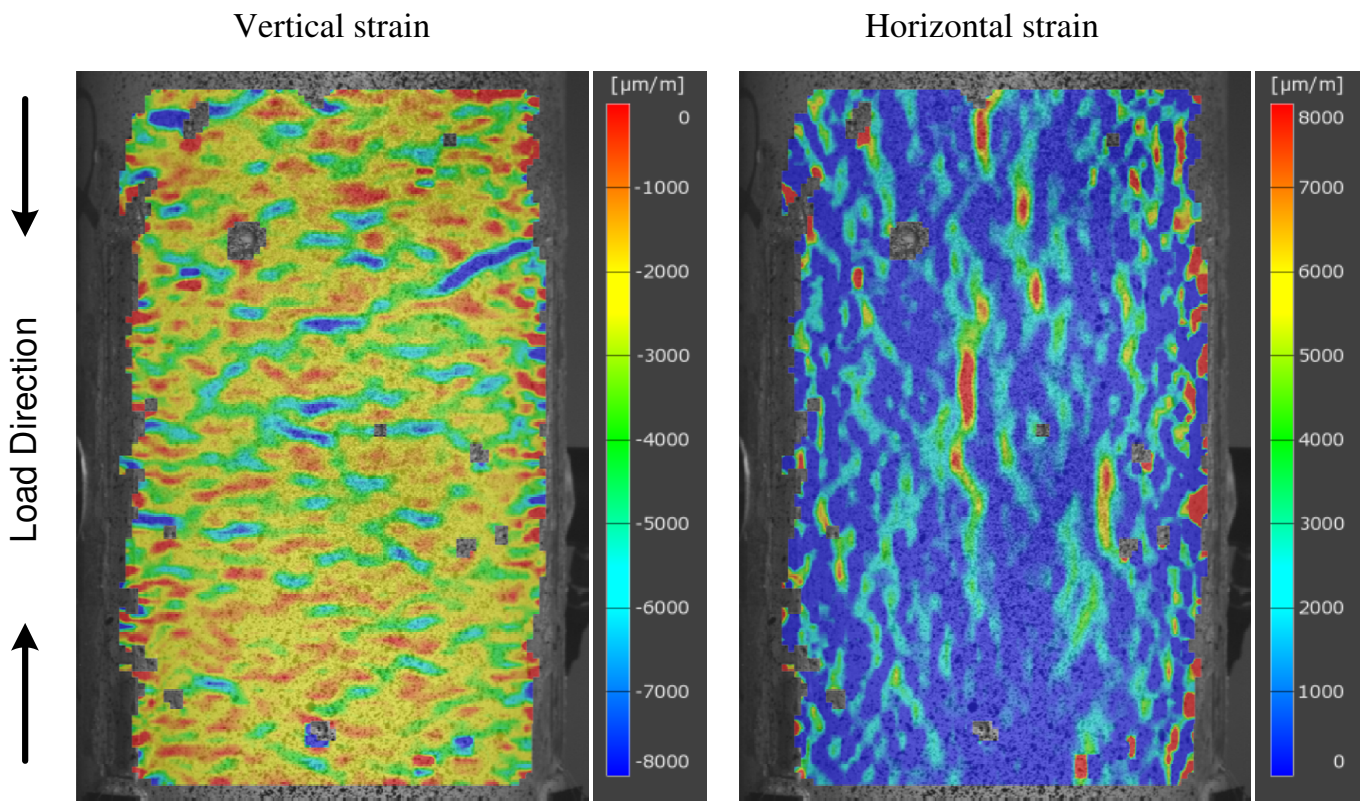

Figure 7: Strain distribution at specimen surface at $50 \%$ fatigue life under top load $\mathrm{S}_{\max }$ taken by digital image correlation with ARAMIS. Left vertical and right horizontal strain components. 
They show clearly a strong inhomogeneous distribution of strains for the vertical (left) as well as for the horizontal (right) strain component Furthermore they document a strong dependency of direction (anisotropy) as well as partly a very high local concentration of stains.

These results can lead to the conclusion that strong inhomogeneous distributions of stress in concrete structure are possible.

State of cracks: With the help of the destructive investigation by optical microscopy, the structure of micro-cracks was investigated at four different states of fatigue life. A quantitative analyze was performed, see Figure 8. Among other things the average crack widths as well as the sum of crack length were determined in the investigated area.

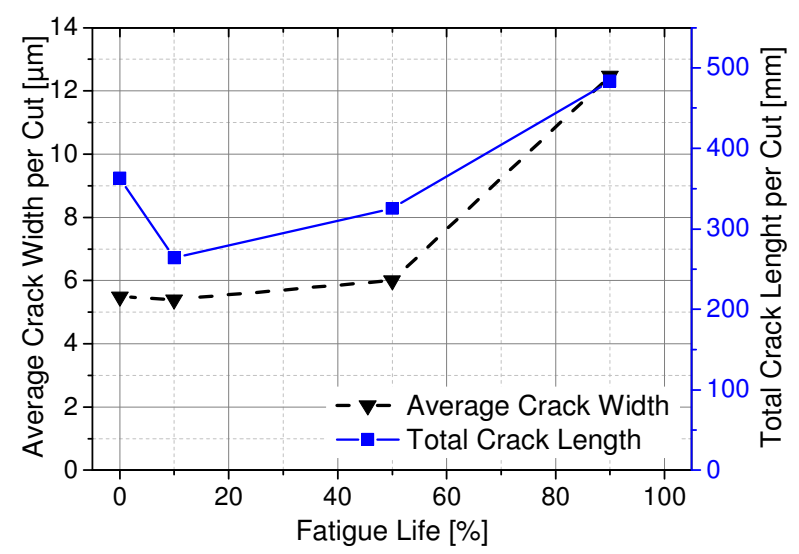

Figure 8: Observed development of average microcrack width and sum of micro-crack length.

It must be considered that every state of fatigue life was determined at another specimen because of the destructive method. Therefore an observation of the development of a precise crack structure in a specimen is not possible. Based on that fact a general scatter is shown in the outcomes. However, in both measured values a very similar tendency could be seen. In phase I and II no significant development in the existing micro-crack structure was determined. Even the crack length shows a minor decrease. Only at the end of the fatigue life in phase III a significant increase in the micro-crack structure was observed.

These results are in correlation with the determined developments of the acoustic emission hit rate (see Figure 5) as well as with the results of the residual static strength which also shows only a significant change in phase III. The strong respectively partly very significant changes in the material behavior during phase I and II are therefore assumedly caused by strong time dependent processes in the material structure.

\section{ANALYSIS AND DISCUSSION}

\subsection{Derived process within material}

Based on the above presented experimental results an explanation of the possible processes in the material structure under fatigue loadings is presented in the following. In general the correlation in the developments of the various measured values indicates that prior viscoplastic deformations in the hardened cement paste are responsible for the strong changes of the material behavior. This applies especially for phase I and II of the fatigue process.

Initial state: Because of the strong heterogeneous material structure of concrete and the very different material properties of the several components a distinct state of internal stresses appears during the process of hydration. This leads also to a distinct structure of micro-cracks in the hardened cement paste with fine and arbitrary oriented micro-cracks. Thereby the unloaded state of concrete is quasi pre-damaged.

Processes in phase I and II: Under external compressive loading a strongly inhomogeneous stress distribution occurs in the material structure, as can be seen in Figure 7. Based on the stiffness differences between aggregates and hardened cement paste, high stress concentrations are developed between big and nearby arranged aggregates. These are predominantly oriented in parallel to the external load direction. This state is schematically illustrated in Figure 9 (left). There were high stresses generated while in the surrounding areas significantly lower stresses exists. In these areas of stress concentration the existing micro-cracks in the hardened cement paste, which are orientated perpendicularly to the load direction, will be 
pressed together. This is illustrated in the left part of Figure 9 (left). Furthermore, additional visco-plastic deformations in the hardened cement paste will be activated. In contrast to this the areas with lower stresses remain elastic. At this point rarely acoustic emissions were measured in the experiments (see Figure 5).

If the loading will be reduced (during unloading) the surrounding areas with lower stresses and elastic behavior will deform back nearly complete. This state is illustrated in Figure 9 (right). Because of the areas in hardened cement paste with load concentrations and visco-plastic deformations which are not able to deform back tension stress will be generated there. The consequence is that these micro-cracks in the hardened cement paste which are oriented normally to the load direction will be opened and also grow based on this tension stresses. Probably new micro-cracks are rarely generated there because the existing microcrack structure absorbs the tension stress. By these opening processes in the existing microcrack structure during the unloading process significant measureable acoustic emissions are generated as well as the hardened cement paste structure will be clearly loosened. The here described processes in the hardened cement paste leads finally to the changes in the stressstrain-relationship which were shown in Figure 4. Under loading an effect of stiffening based on the closing of the micro-cracks occurs. In the state nearby the unloaded condition the loosening in the concentration areas leads to a significant stiffness reduction of the hardened cement paste.

Processes in phase III: Based on the reached degree of damage in the structure only in phase III a significant and strong increasing generation of micro-cracks begins. This fact was shown by the acoustic emission in Figure 5 as well as by the analyzed states of micro-crack structure in Figure 8. The reasons for this are probably local losses of bearing capacity in areas of high load concentrations. They lead to an increasing loose of bearing capacity in the complete specimen. The increasing micro-cracks merges to macrocracks which finally composes fracture surfaces for the fatigue failure.

\section{Processes within phase I and II at meso scale}

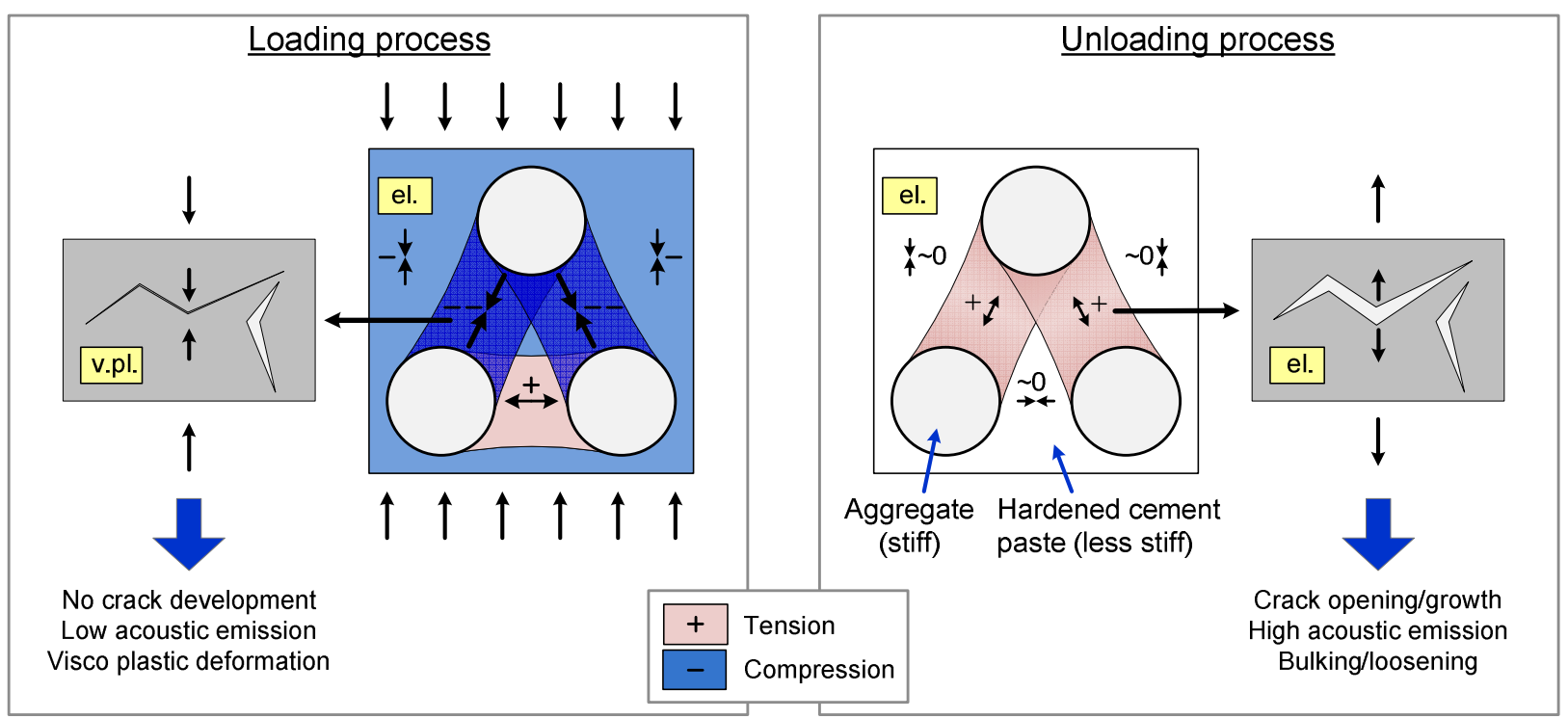

Figure 9: Schematic illustration of processes occurring within the concrete structure under loading (left) and under unloading process (right). 


\subsection{Fatigue damage}

After a possible description of the processes occurring in the concrete structure during fatigue loading was presented a short consideration of the fatigue damage itself will be given below. In Figure 10 the impact of the fatigue process on the stress-strain-relationship is schematically illustrated. Basically the fatigue process leads to permanent deformations as well as to changes of the material stiffness. For concrete typically a linear elastic behavior is assumed what is described with $\mathrm{E}_{0}$.

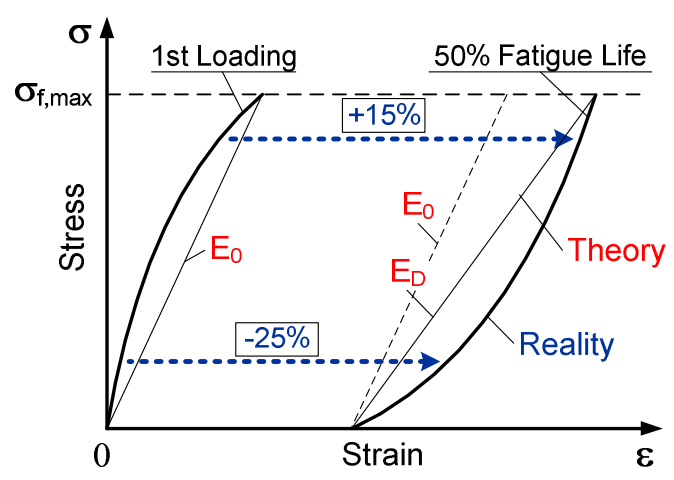

Figure 10: Schematic illustration of the impact of fatigue damage on stress-strain-relationship.

The effect of material damage on the material behavior is commonly taken in to account as a reduction of the material stiffness with the help of a scalar damage variable D:

$$
E_{D}=E_{0}(1-D)
$$

This approach is illustrated with the straight lines in Figure 10. In comparison to the real curve of stress-strain-relationship damaged by cyclic loading it can be clearly seen that this approach is not adequate to characterize the real behavior. The change of the stress-strainrelationship is strongly stress dependent and it is not possible to describe this change by a scalar damage variable. While at the lower stress level a significant decrease of stiffness occurs at the upper stress level a clear increase of stiffness takes place. Within the performed tests after $50 \%$ of fatigue life these stiffness changes amounts $-25 \%$ at lower and $+15 \%$ at upper stress level that also can be seen in
Figure 10. Based on this facts for a realistic description of the material behavior of concrete a stress dependent approach for damage $\mathrm{D}(\sigma)$ is necessary:

$$
E_{D}(\sigma)=E_{0}(1-D(\sigma))
$$

Such an approach is only possible to realize based on a further extensive experimental investigation.

\section{CONCLUSIONS}

In the here presented investigation the damage process in concrete under high-cycle compressive loading has been observed. Thereby with the help of several destructive and non-destructive measurement methods the damage process in concrete was considered both at a macro- as well as at a micro-level. The following results were obtained within this investigation:

- The complete stress-strain-relationship is significant changed during the fatigue process.

- Hardened cement paste at the initial state is characterized by a fine microcrack structure which plays a major role for the fatigue process.

- Under cyclic compressive loading a strong inhomogeneous strain and stress distribution occurs in the material structure containing high local concentrations.

- A significant development in microcrack structure could only be determined at phase III of fatigue process.

- The observed complex behavior of concrete is substantially defined by its heterogeneous material structure.

Based on these experimental results a possible description of the occurring processes in the material structure during the fatigue process has been derived. Therein visco-plastic deformations of hardened cement paste play a substantial role for the changes taking place in the material behavior during fatigue process. Furthermore, it was pointed out that the effect of the fatigue damage on the stress-strain- 
relationship is a strong stress-dependent value. This effect could not be described suitable by a scalar damage value $\mathrm{D}$.

Based on the here presented results continuative investigations are intended to get a more detailed understanding of the fatigue process in concrete.

\section{REFERENCES}

[1] Bahn, B. Y. \& C. T. Hsu (1998). "StressStrain Behavior of Concrete under Cyclic Loading." ACI Materials Journal 95(2): 178-193.

[2] Bazant, Z.P. \& K. Xu (1991). Size Effect in Fatigue Fracture of Concrete. ACI Materials Journal 88(4); pp. 390-399.

[3] Breitenbücher, R. \& H. Ibuk (2006). Experimentally based investigations on the degradation-process of concrete under cyclic load. Materials and Structures 39; pp. 717-724.

[4] Cornelissen, H. A. W. \& H. W. Reinhardt (1984). "Uniaxial tensile fatigue of concrete under constant-amplitude and programme loading." Magazine of Concrete Research 36(129): 216-226.

[5] Dyduch, K., M. Szerszeń, et al. (1994). "Experimental investigation of the fatigue strength of plain concrete under high compressive loading." Materials and Structures 27(9): 505-509.

[6] Gao, L. \& T.T.C. Hsu (1998). Fatigue of concrete under uniaxial compression cyclic loading. ACI Materials Journal 95(5); pp. 575-581.

[7] Hohberg, R. (2004). About Fatigue Behavior of Concrete. $\mathrm{PhD}$ Thesis, Technische Universität Berlin, Berlin (in German).

[8] Holmen, J.O. (1979). Fatigue of concrete by constant and variable amplitude loading. $\mathrm{PhD}$ Thesis, University of Trondheim, Norway.

[9] Kim, J.-K. \& Y.-Y. Kim (1996). "Experimental study of the fatigue behavior of high strength concrete." Cement and Concrete Research 26(10): 1513-1523.
[10] Klausen, D. (1978). Strength and Damage of Concrete by frequently repeated Stress. PhD Thesis, Technische Hochschule Darmstadt, Darmstadt (in German).

[11]Mehmel, A. \& E. Kern (1962). Elastic and plastic deformation in concrete under cyclic compressive and constant load, Heft 153, Deutscher Ausschuss für Stahlbeton, Berlin (in German).

[12]Oh, B. H. (1991). "Fatigue-life distributions of concrete for various stress levels." ACI Materials Journal 88(2): 122128.

[13]Petkovic, C. \& S. Rosseland (1992). High strength concrete SP3 - Fatigue, Report 3.2 Fatigue of high strength concrete. SINTEF Structural Engineering - FCB. Trondheim.

[14] Shah. S.P. \& S. Chandra (1970). Fatigue of concrete subjected to cyclic and sustained loading. ACI Journal 67; pp. 816-825.

[15] Spooner, D.C. \& J.W. Dougill (1975). A quantitative assessment of damage sustained in concrete during compressive loading. Magazine of Concrete Research 27(92); pp. 151-160.

[16] Suresh, S. (1994). Fatigue of materials, Cambridge University Press.

[17]Tepfers, R. \& T. Kutti (1979). "Fatigue strength of plain, ordinary, and lightweight concrete." ACI Journal 76(5): 635-652.

[18]Thiele, M. (2015). Experimental investigation and analysis of damage evolution in concrete due to high-cycle fatigue loading. $\mathrm{PhD}$ Thesis, Technische Universität Berlin, Berlin (in German)

[19] Toumi, A., A. Bascoul, et al. (1998). Crack propagation in concrete subjected to flexural cyclic loading. Materials and Structures 31: 451-458.

[20] van Ornum, J. L. (1903). "Fatigue of cement products." Transactions ASCE 51: 443-451.

[21]Wefer, M. (2010). Material behavior and design values of UHPC under uniaxial fatigue load. $\mathrm{PhD}$ Thesis, Leibnitz Universität Hannover, Hannover (in German). 